\title{
Teor de metionina + cistina total para codornas de corte do grupo genético EV2 durante o período de crescimento
}

\author{
[Total methionine + cystine diet content for EV2 strain of European quail \\ during the growing period] \\ F. Ferreira ${ }^{1}$, G.S.S. Corrêa $a^{2}$, A.B. Corrêa $a^{2}$, M.A. Silva ${ }^{3,8}$,V.P.S. Felipe ${ }^{1}$, L.S. Freitas ${ }^{1}$, \\ R.R. Wenceslau', C.A.R. Lima, , G.G. Santos ${ }^{5}$, R.M. Godinho ${ }^{6}$, \\ J.G. Caramori Junior ${ }^{2}$, C.H.F. Vasconcellos ${ }^{7}$ \\ ${ }^{1}$ Alunos de pós-graduação - EV-UFMG - Belo Horizonte, MG \\ ${ }^{2}$ Universidade Federal de Mato Grosso - FAMEV - Cuiabá, MT \\ ${ }^{3}$ Escola de Veterinária - UFMG - Belo Horizonte, MG \\ ${ }^{4}$ Universidade Federal Rural do Rio de Janeiro - Seropédica, RJ \\ ${ }^{5}$ Pesquisadora Embrapa Gado de Leite - Coronel Pacheco, MG \\ ${ }^{6}$ Aluno de graduação - EV-UFMG - Belo Horizonte, MG \\ ${ }^{7}$ Instituto Federal de Educação - Ciência e Tecnologia de Mato Grosso, MT \\ ${ }^{8}$ Bolsista de produtividade do $\mathrm{CNPq}$
}

\begin{abstract}
RESUMO
Avaliou-se o efeito de diferentes porcentagens de inclusão de metionina + cistina sobre o desempenho de codornas de corte durante as fases inicial - nascimento ao $21^{\circ}$ dia - e total de criação - nascimento a $35^{\circ}$ dia de idade. Foram utilizadas 288 codornas, de ambos os sexos, distribuídas em delineamento inteiramente ao acaso, com seis porcentagens de inclusão de metionina + cistina total, 0,$73 ; 0,79 ; 0,85 ; 0,91 ; 0,97$ e $1,03 \%$, quatro repetições e 12 aves por unidade experimental. As variáveis avaliadas foram peso corporal, ganho de peso, consumo e conversão alimentar do nascimento ao $21^{\circ}$ dia e do nascimento ao $35^{\circ}$ dia de idade. Verificou-se efeito quadrático da inclusão do nascimento ao $21^{\circ}$ dia de idade para todas as características avaliadas, observando melhor desempenho com $0,97 \%$ de metionina + cistina para peso corporal e ganho de peso, e 0,96\% para consumo e conversão alimentar. Houve efeito quadrático da adição nível de metionina + cistina do nascimento ao $35^{\circ}$ dia de idade para peso corporal, ganho de peso e consumo alimentar, com melhor desempenho com 0,$95 ; 0,95$ e $0,96 \%$, respectivamente. A exigência de metionina + cistina para máximo ganho de peso na fase inicial foi de $0,97 \%$, e para fase total de criação $0,95 \%$.
\end{abstract}

Palavras chave: codorna, desempenho, exigência nutricional, ganho de peso

\begin{abstract}
The effect of total methionine + cystine on performance of European quail EV2 strain during two phases of the growth period (from hatch to 21 days and from hatch to 35 days of age) were evaluated in a completely randomized experimental design, with six levels of methinine + cystine $(.73 ; .79 ; .85 ; .91 ; .97$ and 1.03), four replicates and 12 quails per experimental unit. Body weight, weight gain, feed intake and feed:weight gain ratio were recorded from hatch to 21 days and from hatch to 35 days of age. The quadratic effect of methionine + cystine was observed for all traits measured from hatch to 21 days of age. Highest body weight and weight gain were estimated for quails fed $.95 \%$ methionine + cystine diets, while better feed intake and feed:weight gain ratio were estimated for those fed $.96 \%$ diets. The quadratic effects of methionine + cystine levels on body weight, weight gain and feed intake were also observed from hatch to 35 days of age, with estimated highest performance for quails fed $.95 \%$; .95\%; and $.96 \%$ diets, respectively. Methionine + cystine requirement for EV2 strain is $.97 \%$ from hatch to 21 days of age and $.97 \%$ from hatch to 35 days of age.
\end{abstract}

Keywords: quail, performance, nutritional requirement, weight gain

Recebido em 21 de novembro de 2011

Aceito em 12 de janeiro de 2012

E-mail: fabianaferreira@ zootecnista.com.br 


\section{INTRODUÇÃO}

Em função do potencial altamente produtivo das codornas de corte, e com a modernização da produção animal, a exploração comercial dessas aves encontra-se em expansão. Entretanto, assim como em outras atividades avícolas, dentre os fatores que incidem sobre o custo de produção, a alimentação representa aproximadamente $75 \%$ do custo total, e destes, cerca de $25 \%$ correspondem à proteína da dieta (Freitas et al., 2005). As dietas comumente formuladas para codornas são baseadas em exigência de proteína bruta, o que pode acarretar consumo excessivo de aminoácidos. A digestão e o metabolismo desses aminoácidos em excesso geram incremento calórico corporal desnecessário, provocando aumento da excreção de ácido úrico, com maior gasto de energia (Pinto et al., 2003).

Atualmente, com a utilização de aminoácidos sintéticos nas formulações, tem sido possível reduzir a quantidade de proteína bruta, visando atender as exigências dos animais em aminoácidos essenciais, maximizando a utilização destes para a síntese proteica e minimizando seu uso como fonte de energia, favorecendo, assim, o máximo desempenho do animal.

A metionina é um aminoácido de grande importância na nutrição de codornas, pois é um aminoácido essencial e o primeiro limitante para aves. Além disso, a metionina e a cistina são consideradas aminoácidos fisiologicamente essenciais para mantença, crescimento e para o desenvolvimento das penas (Pinto et al., 2003). No organismo, a metionina pode ser catabolizada à cistina, porém o contrário não ocorre, sendo então importante conhecer o requerimento adequado desse aminoácido a fim de não haver falta de metionina no organismo das codornas. Assim, a realização de pesquisas visando estabelecer as exigências nutricionais de codornas de corte torna-se importante, pois conhecer a exigência de cada nutriente possibilita a adequação de programas nutricionais específicos para cada grupo genético, permitindo a expressão máxima do potencial genético da espécie, ao menor custo de produção, e, consequentemente, maior lucratividade.

Corrêa et al. (2006), ao avaliarem a exigência de metionina + cistina total para codornas de corte
EV1 em crescimento, encontraram maior ganho de peso quando utilizaram $0,95 \%$ na fase inicial - de sete a 21 dias - e $0,73 \%$ na fase final de criação - de 22 a 42 dias de idade. Ainda, Corrêa et al. (2010), ao trabalharem com os mesmos níveis de porcentagens de inclusão - 0,73 a $1,03 \%$ de metionina + cistina para codornas de corte EV2 do sétimo ao $21^{\circ}$ dia de idade -, observaram aumento no peso corporal e ganho de peso das codornas alimentadas com dietas contendo $0,95 \%$ e $1,03 \%$ de metionina + cistina total para as fases inicial - do sétimo ao $21^{\circ}$ dia e total de criação - do sétimo ao $42^{\circ}$ dia de idade.

Resultados de pesquisas referentes à exigência de metionina + cistina para codornas ainda são controversos, além de não haver trabalhos relacionados a essa exigência a partir do nascimento até 35 dias de idade. Portanto, objetivou-se com este trabalho estabelecer a exigência de metionina + cistina para codornas de corte do grupo genético EV2 do nascimento ao $35^{\circ}$ dia de idade.

\section{MATERIAL E MÉTODOS}

Utilizaram-se 288 codornas de corte EV2, de ambos os sexos, do nascimento ao $21^{\circ}$ dia e do nascimento ao $35^{\circ}$ dia de idade, com peso médio inicial de $9,16 \mathrm{~g}$. $\mathrm{O}$ experimento foi realizado em delineamento inteiramente ao acaso, com seis níveis de metionina + cistina, 0,$73 ; 0,79 ; 0,85$; 0,$91 ; 0,97$ e $1,03 \%$, quatro repetições e 12 aves por unidade experimental. As aves foram alojadas em baterias de arame galvanizado com dimensões de $0,82 \mathrm{~m}$ de largura $\mathrm{x} 0,41 \mathrm{~m}$ de profundidade $\mathrm{x} 0,27 \mathrm{~m}$ de altura por unidade experimental, equipadas com bebedouro copo e comedouro tipo calha. Durante a fase inicial de crescimento das codornas, o aquecimento foi feito com lâmpadas incandescentes de 100 Watts na primeira semana e de 60 Watts na segunda semana, e durante toda a fase experimental foi adotado o programa de luz de 24 horas.

As dietas foram formuladas com base nas informações nutricionais de composições dos ingredientes apresentadas por Rostagno et al. (2005), e, para atender as exigências nutricionais das codornas, utilizou-se o NRC (Nutrient..., 1994), exceto para metionina + cistina (objeto de estudo). A dieta basal (Tab. 1) foi formulada à 
base de milho e farelo de soja, contendo $23,9 \%$ de proteína bruta (PB) e $2900 \mathrm{kcal}$ de EM/kg de dieta, a qual foi suplementada com cinco níveis de DL-metionina (99\%), em substituição ao amido de milho, o que corresponde às porcentagens de 0,73 - dieta basal sem suplementação -; 0,79; 0,85; 0,91; 0,97 e 1,03\% de metionina + cistina total, permanecendo as dietas isocalóricas e isoproteicas. As dietas foram fornecidas à vontade, e os bebedouros limpos diariamente.

Tabela 1. Composição percentual e calculada da dieta basal

\begin{tabular}{|c|c|}
\hline Ingrediente & $\%$ \\
\hline Milho & 53,469 \\
\hline Farelo de soja & 41,954 \\
\hline Calcário & 1,072 \\
\hline Óleo de soja & 1,016 \\
\hline Fosfato bicálcico & 0,960 \\
\hline Amido & 0,500 \\
\hline Suplemento mineral e vitamínico ${ }^{1}$ & 0,500 \\
\hline Sal comum & 0,265 \\
\hline L-treonina & 0,265 \\
\hline Total & 100,00 \\
\hline \multicolumn{2}{|l|}{ Composição calculada } \\
\hline Proteína bruta (\%) & 23,886 \\
\hline Energia metabolizável (kcal/kg) & 2.900 \\
\hline Cálcio $(\%)$ & 0,800 \\
\hline disponível (\%) & 0,300 \\
\hline Sódio (\%) & 0,150 \\
\hline \multicolumn{2}{|l|}{ Aminoácidos totais } \\
\hline Lisina $(\%)$ & 1,300 \\
\hline Metionina + cistina $(\%)$ & 0,731 \\
\hline Triptofano $(\%)$ & 0,305 \\
\hline Metionina (\%) & 0,464 \\
\hline Arginina $(\%)$ & 1,612 \\
\hline Isoleucina $(\%)$ & 1,040 \\
\hline Valina $(\%)$ & 1,107 \\
\hline \multicolumn{2}{|c|}{$\begin{array}{l}{ }^{1} \text { Composição por quilo de produto: vit. } \mathrm{A}- \\
2.000 .000 \mathrm{UI} \text {; vit. } \mathrm{D}_{3}-375.000 \mathrm{UI} \text {; vit. } \mathrm{E}-3.750 \mathrm{mg} \text {; } \\
\text { vit. } \mathrm{k}_{3}-500 \mathrm{mg} \text {; vit. } \mathrm{B}_{1}-250 \mathrm{mg} \text {; vit. } \mathrm{B}_{2^{-}} 750 \mathrm{mg} \text {; vit. } \mathrm{B}_{6} \\
-500 \mathrm{mg} \text {; vit. } \mathrm{B}_{12}-3.750 \mathrm{mcg} \text {; niacina- } 6.250 \mathrm{mg} \text {; ac. } \\
\text { pantotênico- } 2.500 \mathrm{mg} \text {; biotina- } 10 \mathrm{mg} \text {; ac. fólico- } \\
125 \mathrm{mg} \text {; colina-75.000mg; selênio-45mg; iodo-175mg; } \\
\text { ferro-12.525mg; cobre-2.500mg; manganês- } \\
\text { 19.500mg; zinco- } 13.750 \mathrm{mg} \text {; avilamicina-15.000mg; } \\
\text { narasin-12.250mg; B.H.T.-500mg; vit.C-12.500mg. }\end{array}$} \\
\hline
\end{tabular}

Para avaliação do desempenho, foram registrados, em cada unidade experimental, peso corporal (g), ganho de peso (g), consumo alimentar (g) e conversão alimentar ( $\mathrm{g}$ de ração/g de peso) do nascimento ao $21^{\circ}$ dia e do nascimento ao $35^{\circ}$ dia de idade. $\mathrm{O}$ peso corporal foi avaliado no primeiro, $21^{\circ}$ e $35^{\circ}$ dias de idade, e o ganho de peso obtido por meio da diferença entre o peso inicial e o peso final de cada fase. Para avaliação do consumo alimentar, ao final de cada período as sobras de ração do comedouro de cada unidade experimental foram pesadas e, por diferença entre ração fornecida e sobras, determinou-se o consumo por período (g/ave). A conversão alimentar por ave foi calculada dividindo-se o consumo de ração/ave pelo ganho de peso/ave de cada unidade experimental e em cada período do experimento.

As análises dos dados foram realizadas por meio do programa SAEG (Sistema..., 2009). O efeito da inclusão de metionina + cistina foi calculado por análise de regressão, ao se desdobrarem os graus de liberdade dos fatores em seus componentes linear e quadrático para escolha do modelo de regressão que melhor descrevesse as observações.

\section{RESULTADOS E DISCUSSÃO}

Do nascimento ao $21^{\circ}$ dia de idade, peso corporal, ganho de peso, consumo e conversão alimentar responderam de forma quadrática à inclusão de metionina + cistina da dieta (Tab. 2), de acordo com as respectivas equações de regressão: $\hat{Y}_{i}=-1002,99+2383,02 X_{i}$ 1226,03 $X_{i}^{2} \quad$ (Fig. 1); $\quad \hat{Y}_{i}=-1012,16+$ $2382,97 X_{i}-1225,94 X_{i}^{2}$ (Fig. 2); $\hat{Y}_{i}=$ 1446,28 + 3626,80 $X_{i}-1896,84 X_{i}^{2}$ (Fig. 3); e $\hat{Y}_{i}=12,84-22,61 X_{i}+11,72 X_{i}^{2}$ (Fig. 4). Assim, o peso corporal e o ganho de peso aumentaram até a inclusão de $0,97 \%$ de metionina + cistina total, e o consumo aumentou até a porcentagem estimada de $0,96 \%$. A conversão alimentar diminuiu até $0,96 \%$ de metionina + cistina, porcentagem na qual as codornas apresentaram melhor eficiência na conversão alimentar. 


\section{Ferreira et al.}

Tabela 2. Peso corporal (g), ganho de peso (g), consumo alimentar (g) e conversão alimentar (g/g) das codornas de corte EV2 do nascimento ao $21^{\circ}$ dia de idade, segundo a porcentagem de metionina + cistina da dieta

\begin{tabular}{|c|c|c|c|c|}
\hline $\begin{array}{l}\text { Metionina } \\
(\%)\end{array}$ & $\begin{array}{l}\text { Peso corporal } \\
(\mathrm{g})\end{array}$ & $\begin{array}{l}\text { Ganho de peso } \\
(\mathrm{g})\end{array}$ & $\begin{array}{l}\text { Consumo } \\
\text { alimentar } \\
\text { (g) }\end{array}$ & $\begin{array}{l}\text { Conversão } \\
\text { alimentar } \\
(\mathrm{g} / \mathrm{g})\end{array}$ \\
\hline 0,73 & 76,31 & 67,16 & 176,41 & 2,62 \\
\hline 0,79 & 125,92 & 116,74 & 259,88 & 2,23 \\
\hline 0,85 & 140,55 & 131,43 & 268,22 & 2,04 \\
\hline 0,91 & 139,59 & 130,44 & 268,32 & 2,05 \\
\hline 0,97 & 153,85 & 144,72 & 281,40 & 1,94 \\
\hline 1,03 & 154,33 & 145,20 & 284,60 & 1,96 \\
\hline $\mathrm{CV}$ & 4,30 & 4,61 & 5,46 & 4,39 \\
\hline Significância & $*$ & $*$ & $*$ & $*$ \\
\hline \multicolumn{4}{|c|}{ Equação de regressão } & $\begin{array}{c}\text { Ponto de melhor } \\
\text { desempenho }\end{array}$ \\
\hline Peso corporal & \multicolumn{3}{|c|}{$\hat{Y}_{i}=-1002,99+2383,02 X_{i}-1226,03 X_{i}^{2}\left(\mathrm{R}^{2}=0,92\right)$} & 0,97 \\
\hline Ganho de peso & \multicolumn{3}{|c|}{$\hat{Y}_{i}=-1012,16+2382,97 X_{i}-1225,94 X_{i}^{2}\left(\mathrm{R}^{2}=0,92\right)$} & 0,97 \\
\hline Consumo alimentar & \multicolumn{3}{|c|}{$\hat{Y}_{i}=-1446,28+3626,80 X_{i}-1896,84 X_{i}^{2}\left(\mathrm{R}^{2}=0,86\right)$} & 0,96 \\
\hline Conversão alimentar & \multicolumn{3}{|c|}{$\hat{Y}_{i}=12,84-22,61 X_{i}+11,72 X_{i}^{2} \quad\left(\mathrm{R}^{2}=0,95\right)$} & 0,96 \\
\hline
\end{tabular}

$*$ = Significativo

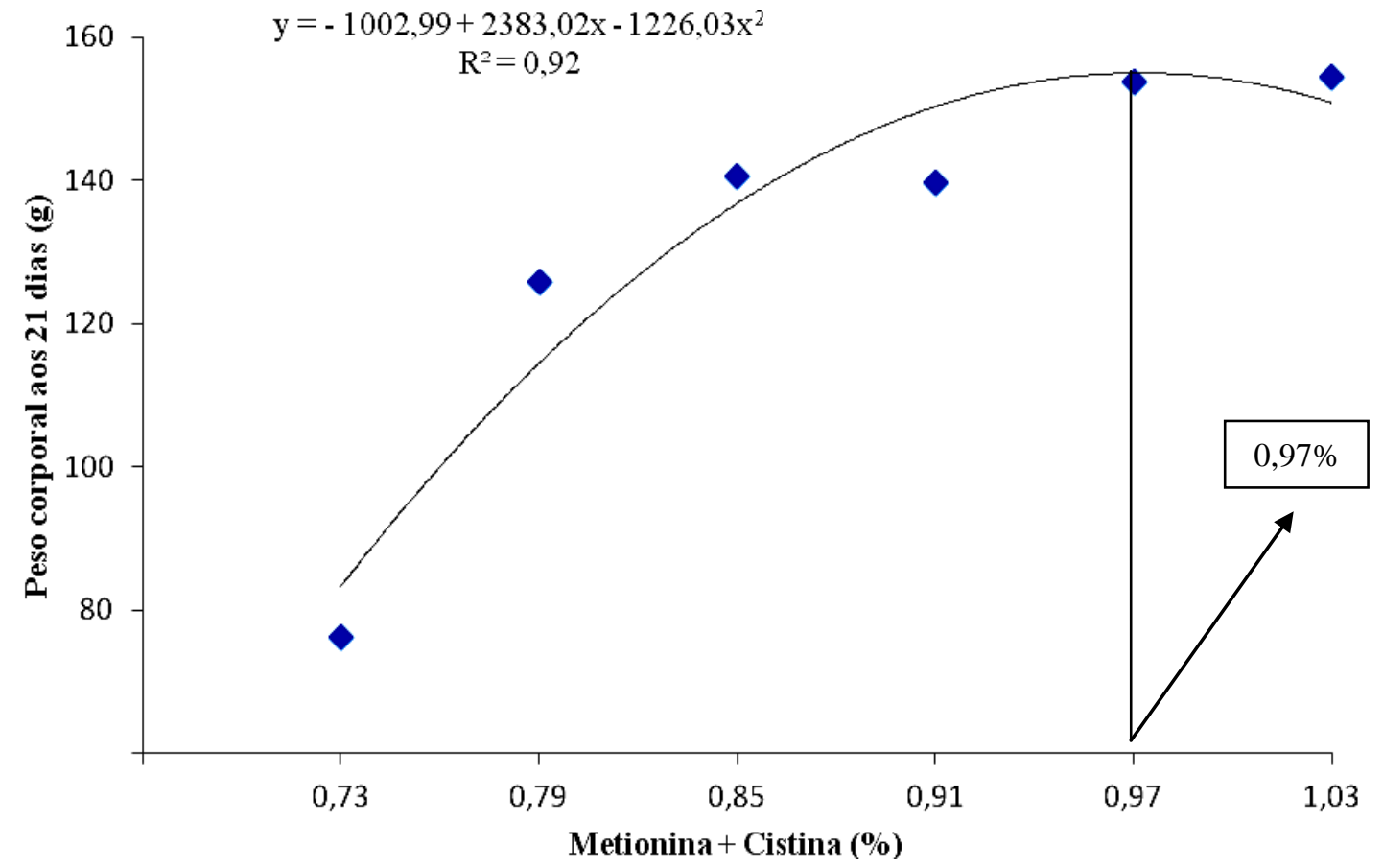

Figura 1. Regressão do peso corporal no $21^{\circ}$ dia de idade de codornas de corte EV2 em relação à porcentagem de metionina + cistina da dieta. 


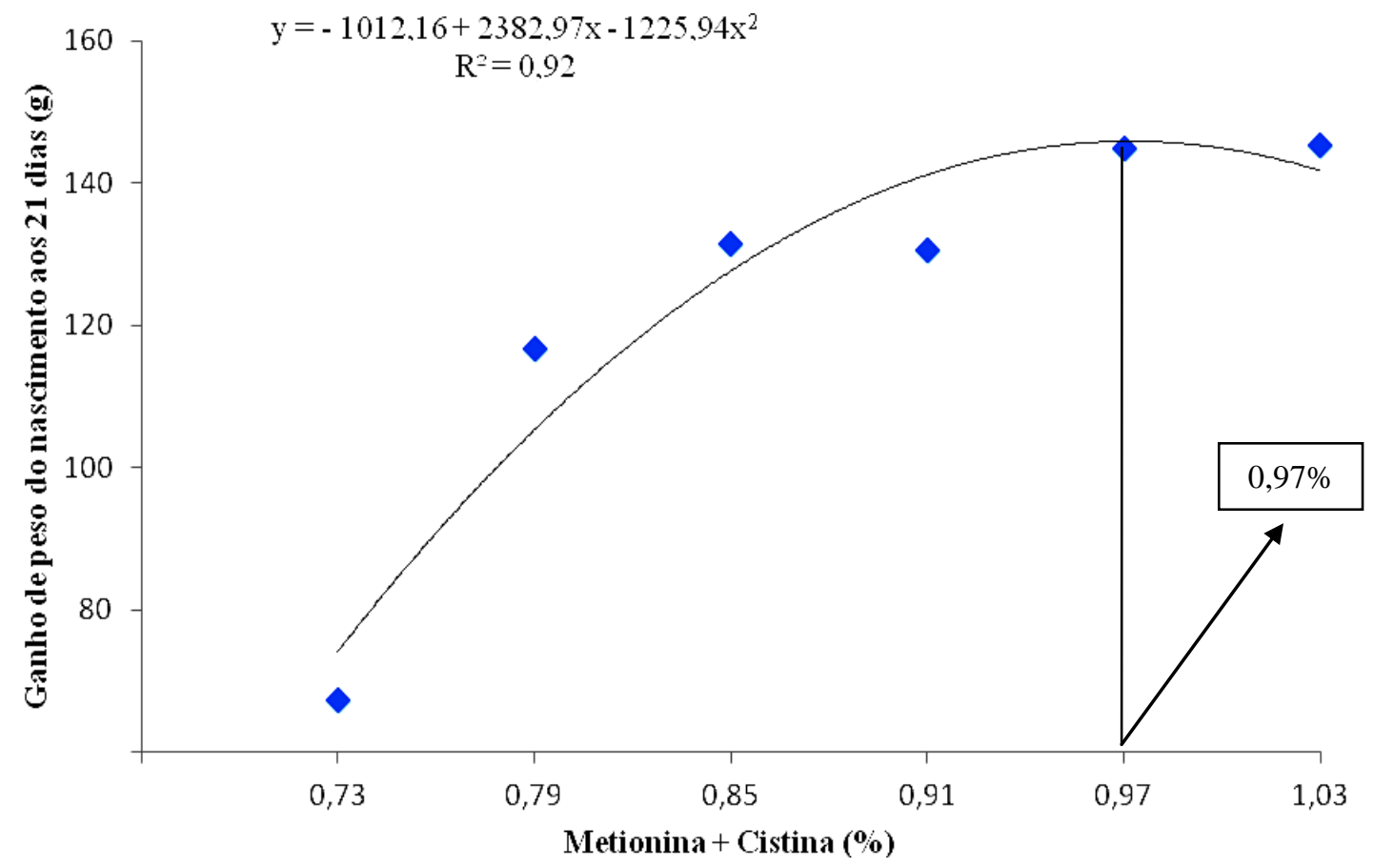

Figura 2. Regressão do ganho de peso do nascimento ao $21^{\circ}$ dia de idade de codornas de corte EV2 em relação à porcentagem de metionina + cistina da dieta.

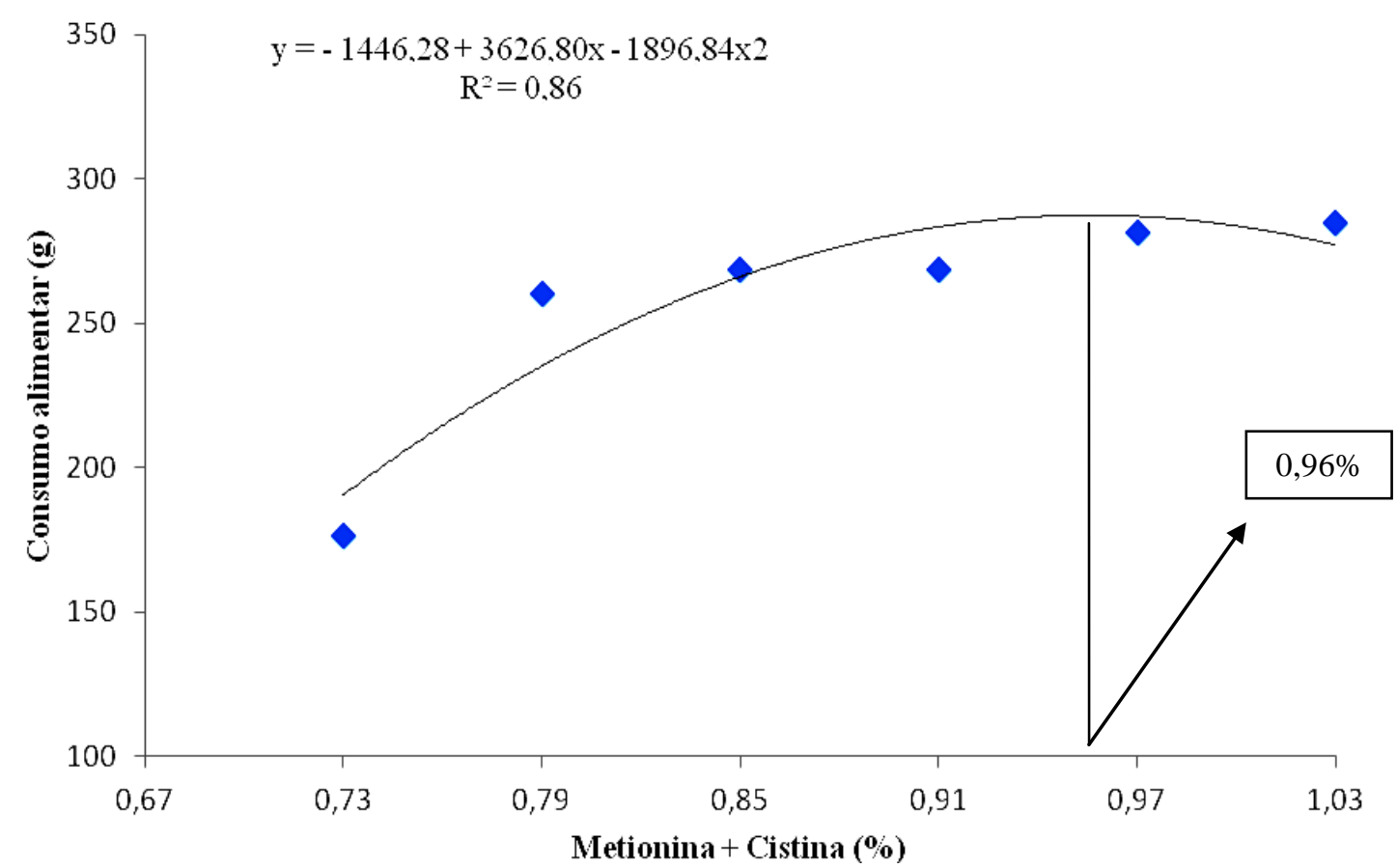

Figura 3. Regressão do consumo alimentar do nascimento ao $21^{\circ}$ dia de idade de codornas de corte EV2 em relação à porcentagem de metionina + cistina da dieta. 


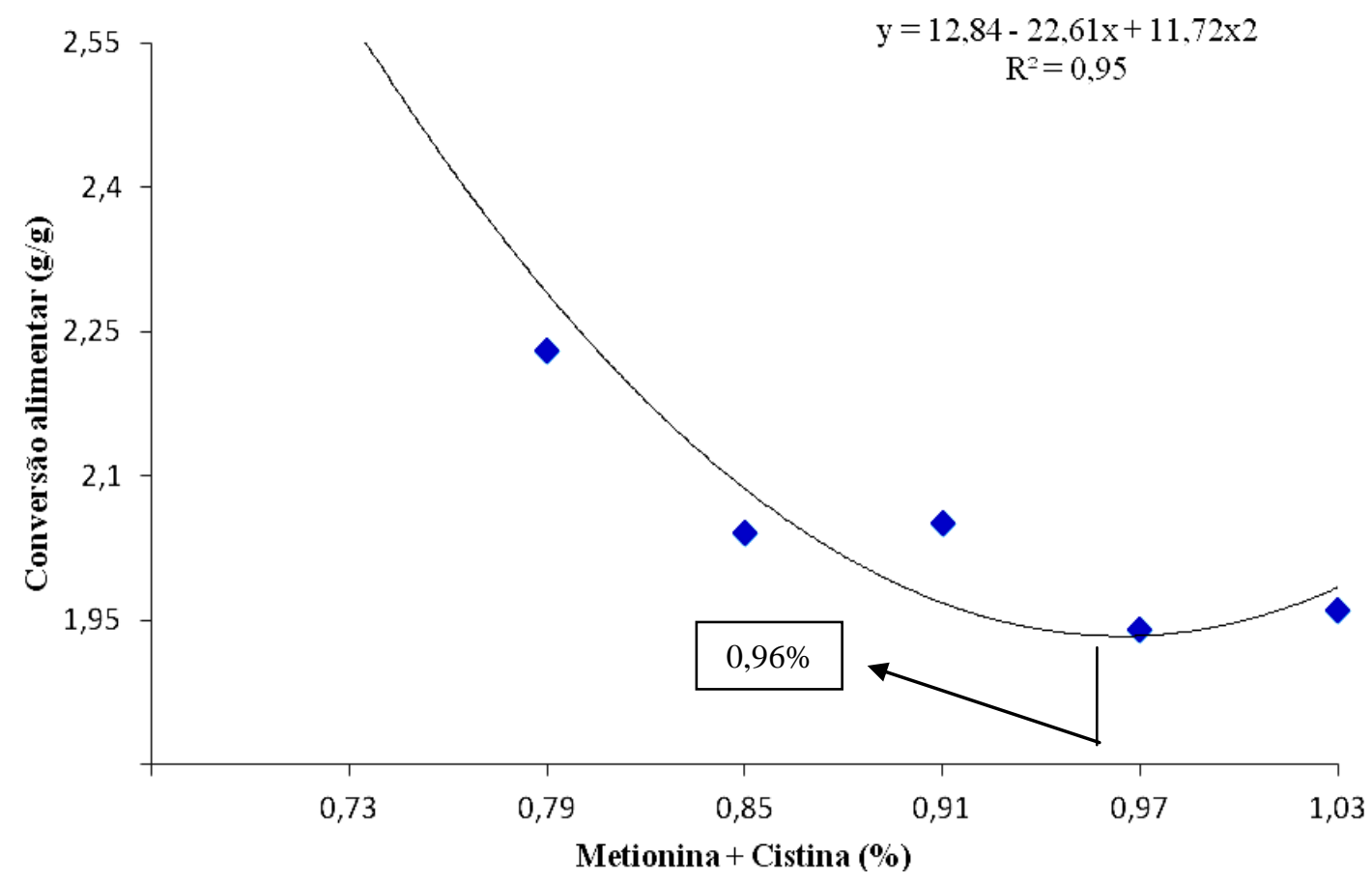

Figura 4. Regressão da conversão alimentar do nascimento ao $21^{\circ}$ dia de idade de codornas de corte EV2 em relação à porcentagem de metionina + cistina da dieta.

A exigência de metionina + cistina para peso corporal e ganho de peso observada neste estudo encontra-se acima do que é preconizado pelo NRC (Nutrient..., 1994), que recomenda 0,75\% de metionina + cistina para codornas em crescimento, porém a recomendação do NRC refere-se à exigência de codornas japonesas; essas, quando comparadas às codornas de corte (europeias) apresentam desempenhos diferentes, pois possuem maior aptidão para postura. $\mathrm{O}$ peso médio das codornas encontrado foi de 131,76g aos 21 dias de idade, enquanto as codornas japonesas atingem peso médio de $87 \mathrm{~g}$ nessa mesma idade.

Como as codornas de corte apresentam maiores peso e taxa de crescimento que as codornas japonesas, são necessárias maiores concentrações de aminoácidos nas dietas para rápido crescimento dessas aves, devido ao alto requerimento para a formação do tecido proteico. Corrêa et al. (2005) verificaram, mediante regressão linear crescente, que codornas alimentadas com dietas contendo 0,73 a $1,03 \%$ de metionina + cistina durante a fase inicial sétimo ao $21^{\circ}$ dia de idade - apresentaram maior ganho de peso na maior porcentagem de metionina + cistina da dieta.

Os resultados encontrados por Torres et al. (2005) e Corrêa et al. (2006; 2010) foram mais altos. Esses autores, os quais trabalharam com 0,73 a $1,03 \%$ de metionina + cistina para codornas de corte do sétimo ao $21^{\circ}$ dia de idade, observaram aumento no peso e ganho de peso das codornas alimentadas com dietas contendo $0,95 \%$ de metionina + cistina total. Essa diferença pode ser atribuída ao fato de os autores anteriormente citados terem avaliado o desempenho das codornas a partir do sétimo dia de idade, não avaliando a primeira semana de vida, período de maior velocidade de crescimento, pois as codornas aos sete dias de idade apresentam um aumento de quase quatro vezes o seu peso ao nascimento.

Observou-se que o consumo alimentar aumentou até a adição de $0,96 \%$ de metionina + cistina, e, provavelmente, após a exigência ter sido atendida começou a ocorrer uma redução no consumo devido ao fato de o excesso de metionina tornar-se tóxico às aves. Murakami et al. (1994) não observaram efeito da porcentagem 
de inclusão de aminoácidos sulfurosos sobre o consumo alimentar de codornas japonesas. Corrêa et al. (2010) também não verificaram efeito significativo da porcentagem de adição de 0,73 a $1,03 \%$ de metionina + cistina sobre o consumo alimentar de codornas de corte em crescimento.

Quanto à conversão alimentar, esta foi influenciada de forma quadrática pela adição de metionina + cistina testadas, observando-se melhor conversão com $0,96 \%$. No entanto, Corrêa et al. (2006) não observaram efeito das porcentagens testadas - 0,$73 ; 0,79 ; 0,85 ; 0,91$; 0,97 e $1,03 \%$ de metionina + cistina - sobre o consumo e a conversão alimentar de codornas de corte, enquanto Corrêa et al. (2010) verificaram comportamento linear decrescente da porcentagem de metionina + cistina, isto é, à medida que foram aumentadas as porcentagens, houve melhora na conversão alimentar de codornas de corte do sétimo ao $21^{\circ}$ dia de idade, sendo a melhor conversão observada com $1,03 \%$ de metionina + cistina.

Houve efeito quadrático dos níveis de metionina + cistina sobre peso corporal, ganho de peso e consumo alimentar das codornas de corte durante a fase total de criação (Tab. 3), segundo as seguintes equações de regressão: $\hat{Y}_{i}=-1193,70$
$+3062,89 X_{i}-1608,58 X_{i}^{2}$ (Fig. 5); $\hat{Y}_{i}=-$ $1202,87+3062,84 X_{i}-1608,49 X_{i}^{2}$ (Fig. 6); e $\hat{Y}_{i}=-2515,45+6689,82 X_{i}-3498,70 X_{i}^{2}$

(Fig. 7), respectivamente. $O$ máximo desempenho foi observado nos níveis de $0,95 \%$ para peso corporal e ganho de peso, e $0,96 \%$ de metionina + cistina total para consumo alimentar.

Os resultados encontrados para peso corporal, ganho de peso e consumo alimentar foram semelhantes aos observados por Ferreira et al. (2010). Esses autores estimaram para máximo peso corporal e ganho de peso com $0,93 \%$ de metionina + cistina para codornas de corte do nascimento ao $35^{\circ}$ dia de idade. Pinto et al. (2003), ao testarem seis porcentagens de metionina + cistina, 0,$55 ; 0,61 ; 0,66 ; 0,72 ; 0,78 \mathrm{e}$ $0,86 \%$, para codornas japonesas em crescimento - do sétimo ao $42^{\circ}$ dia de idade -, observaram efeito linear crescente e recomendaram o nível $0,86 \%$ de metionina + cistina para máximo peso final e ganho de peso. Corrêa et al. (2006) não observaram influência da adição de metionina + cistina testadas sobre peso corporal, ganho de peso, consumo e conversão alimentar de codornas de corte do sétimo ao $42^{\circ}$ dia de idade.

Tabela 3. Peso corporal (g), ganho de peso (g), consumo alimentar (g) e conversão alimentar (g/g) das codornas de corte EV2 do nascimento ao $35^{\circ}$ dia de idade, segundo o nível de metionina + cistina da dieta

\begin{tabular}{ccccc}
\hline $\begin{array}{l}\text { Metionina } \\
(\%)\end{array}$ & $\begin{array}{c}\text { Peso corporal } \\
(\mathrm{g})\end{array}$ & $\begin{array}{c}\text { Ganho de peso } \\
(\mathrm{g})\end{array}$ & $\begin{array}{c}\text { Consumo } \\
\text { alimentar } \\
(\mathrm{g})\end{array}$ & $\begin{array}{c}\text { Conversão } \\
\text { alimentar } \\
(\mathrm{g} / \mathrm{g})\end{array}$ \\
\hline 0,73 & 176,20 & 167,05 & 479,86 & 2,87 \\
0,79 & 239,22 & 230,04 & 630,63 & 2,74 \\
0,85 & 246,52 & 237,40 & 644,75 & 2,72 \\
0,91 & 249,67 & 240,52 & 640,10 & 2,67 \\
0,97 & 265,90 & 256,76 & 687,00 & 2,67 \\
1,03 & 256,92 & 247,80 & 670,46 & 4,71 \\
\hline CV & 4,15 & 4,31 & 4,23 & Ns \\
\hline Significância & $*$ & $*$ & $*$ & Ponto de melhor \\
& \multicolumn{2}{c}{ Equação de regressão } & 0,95 \\
\hline Peso corporal & $\hat{Y}_{i}=-1193,70+3062,89 X_{i}-1608,58 X_{i}^{2}\left(\mathrm{R}^{2}=0,90\right)$ & 0,95 \\
\hline Ganho de peso & $\hat{Y}_{i}=-1202,87+3062,84 X_{i}-1608,49 X_{i}^{2}\left(\mathrm{R}^{2}=0,90\right)$ & 0,96 \\
\hline Consumo alimentar & $\hat{Y}_{i}=-2515,45+6689,82 X_{i}-3498,70 X_{i}^{2}\left(\mathrm{R}^{2}=0,86\right)$ & \\
\hline
\end{tabular}

* = Significativo; ns = Não significativo. 


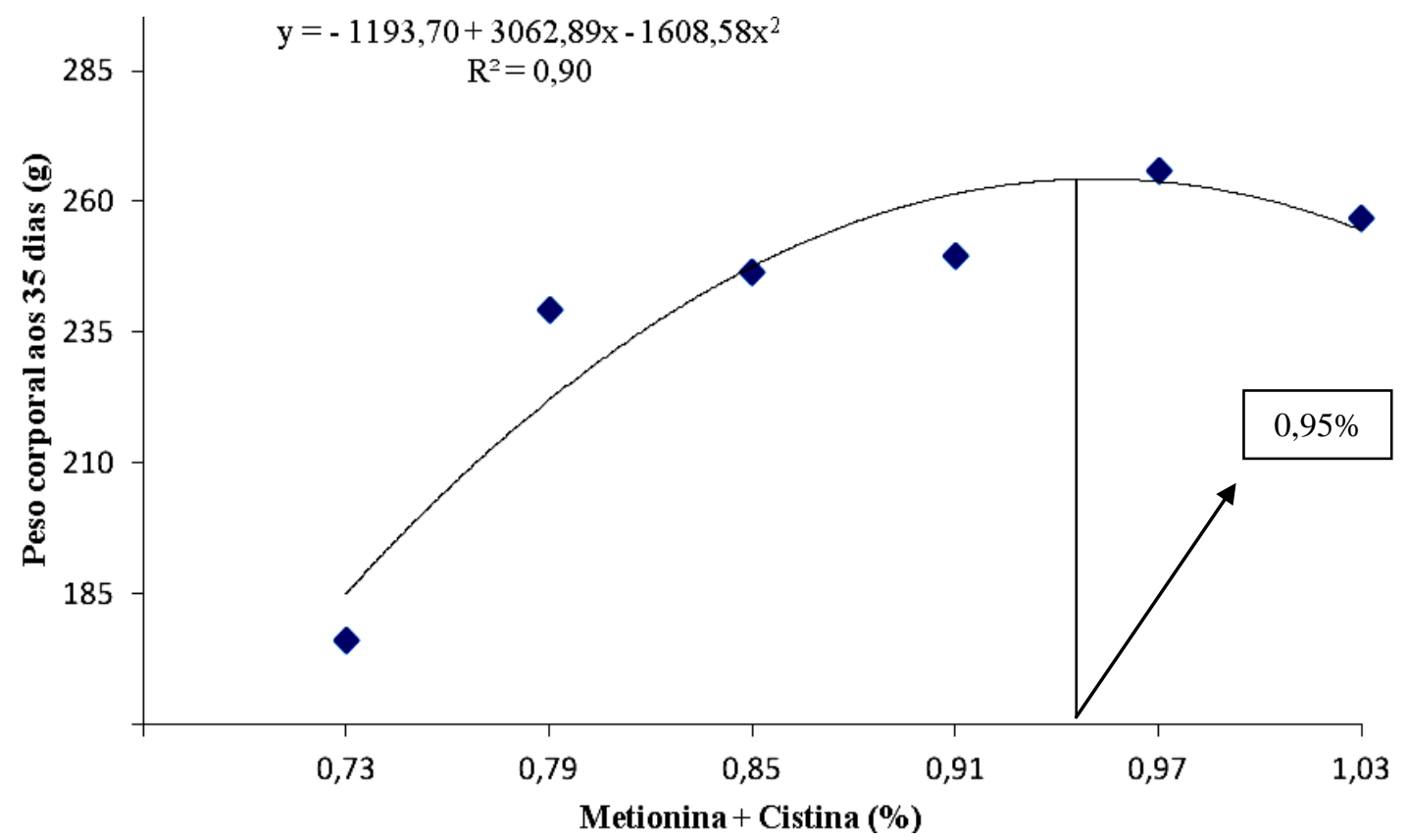

Figura 5. Regressão do peso corporal no $35^{\circ}$ dia de idade de codornas de corte EV2 em relação à porcentagem de metionina + cistina da dieta.

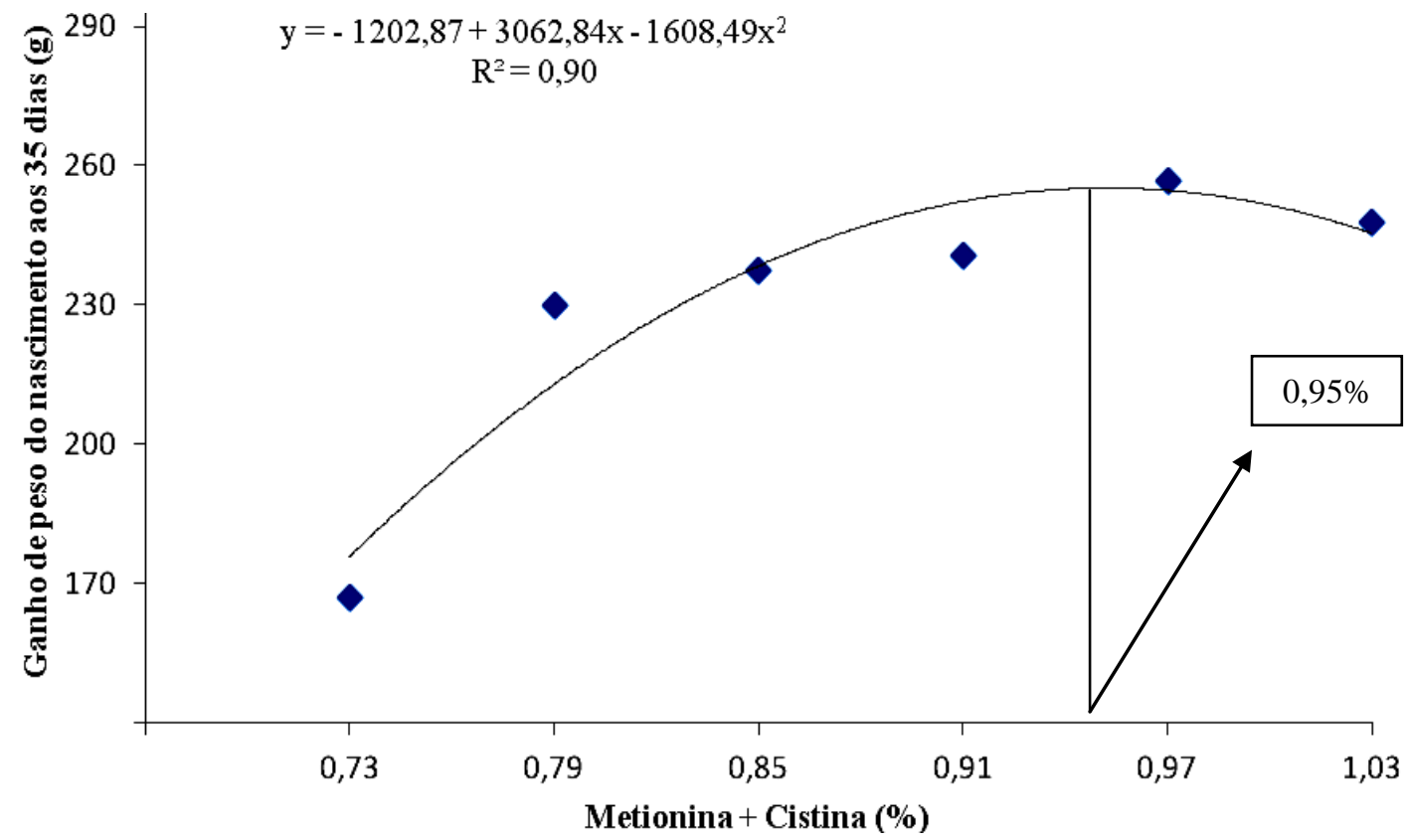

Figura 6. Regressão do ganho de peso do nascimento ao $35^{\circ}$ dia de idade de codornas de corte EV2 em relação à porcentagem de metionina + cistina da dieta. 


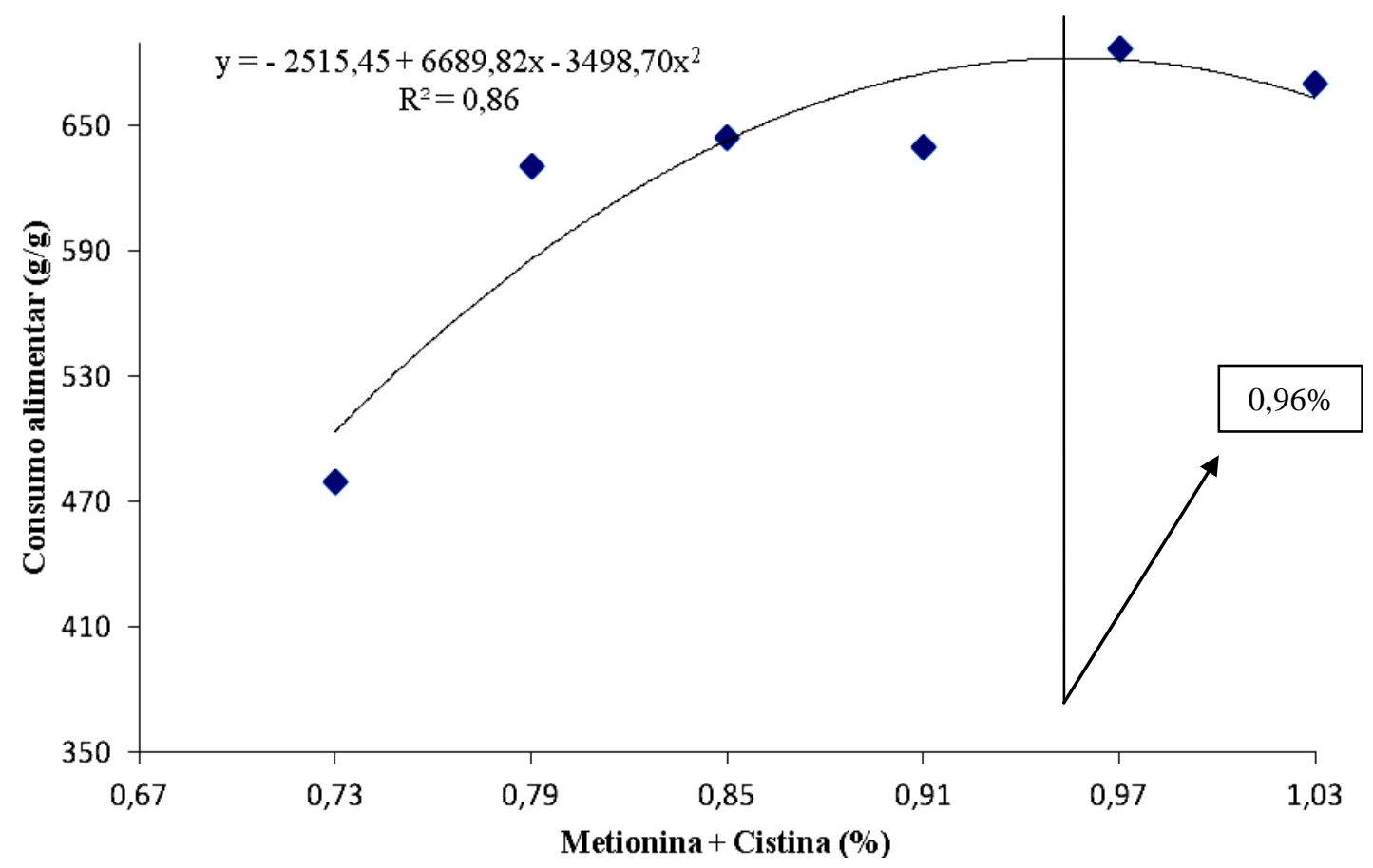

Figura 7. Regressão do consumo alimentar do nascimento ao $35^{\circ}$ dia de idade de codornas de corte EV2 em relação à porcentagem de metionina + cistina da dieta.

Não houve efeito significativo da inclusão de metionina + cistina total testadas sobre a conversão alimentar do nascimento aos 35 dias de idade das codornas de corte. Isso indica que o aumento de metionina + cistina não foi suficiente para promover desequilíbrio aminoácidico que resultasse na alteração do perfil plasmático das aves e que ativasse os mecanismos reguladores do apetite, como descrito por Harper et al. (1970). Corrêa et al. (2010) também não encontraram efeito significativo da inclusão de metionina + cistina sobre a conversão alimentar.

\section{CONCLUSÕES}

A exigência de metionina + cistina para máximo ganho de peso de codornas de corte do nascimento ao $21^{\circ}$ dia de idade é de $0,97 \%$, e para fase total de criação é de $0,95 \%$, correspondendo às relações de 0,75 e 0,73 de metionina + cistina: lisina, respectivamente.

\section{REFERENCIAS}

CORRÊA, G.S.S.; SILVA, M.A.; CORRÊA, A.B. $e t$ $a l$. Níveis de metionina + cistina para híbridos EV1 de codornas europeias no período de crescimento. In: REUNIÃO ANUAL DA SOCIEDADE BRASILEIRA DE ZOOTECNIA, 42., 2005. Goiânia. Anais... Goiânia, GO: SBZ, 2005.

CORRÊA, G.S.S.; SILVA, M.A.; CORRÊA, A.B. et al. Exigência de metionina + cistina total para codornas de corte em crescimento. Arq. Bras. Med. Vet. Zootec., v.58, p.414-420, 2006.

CORRÊA, G.S.S.; SILVA, M.A.; CORRÊA, A.B. et $a l$. Níveis de metionina + cistina para características de desempenho e carcaça em codornas de corte EV2. Arq. Bras. Med. Vet. Zootec., v.62, p.940-947, 2010.

FERREIRA, F.; CORRÊA, G.S.S.; SILVA, M.A. $e t$ al. Desempenho de codornas de corte EV1 do nascimento ao $35^{\circ}$ dia de idade alimentadas com dietas contendo diferentes níveis de metionina + cistina total. In: REUNIÃO ANUAL DA SOCIEDADE BRASILEIRA DE ZOOTECNIA, 47., 2010. Salvador. Anais... Salvador, BA: SBZ, 2010. 
FREITAS, A.C.; FUENTES, M.F.F.; FREITAS, E.R. et al. Efeito de níveis de proteína bruta e de energia metabolizável na dieta sobre o desempenho de codornas de postura. Rev. Bras. Zootec., v.34, p.838846, 2005.

HARPER, A.E.; BENEVENGA, N.J.; WOHLHUETER, R.M. Effects of ingestion of disproportionate amounts of amino acids. Physiol. Rev., v.50, p.428-558, 1970.

MURAKAMI, A.E.; FURLAN, A.C.; TATEISHI, A. et al. Exigência de metionina para codornas japonesas (Coturnix coturnix japonica) em postura. In: REUNIÃO ANUAL DA SOCIEDADE BRASILEIRA DE ZOOTECNIA, 31., 1994, Maringá. Anais... Maringá, PR: SBZ, p.64.

NUTRIENT requeriments of poultry. 9.edição, Washington: National Academy of Sciences, 1994, 155 p.
PINTO, R.; FERREIRA, A.S.; DONZELE, J.L. et al. Exigência de metionina mais cistina para codornas japonesas em crescimento. Rev. Bras. Zootec., v.32, p.1174-1181, 2003.

ROSTAGNO, H.S.; ALBINO, L.F.T.; DONZELE, J.L. et al. Tabelas Brasileiras para Aves e Suínos. Composição de Alimentos e Exigências Nutricionais. Editora UFV, 2005. 183p.

SISTEMA para análise estatística e genética- SAEG, Viçosa, MG: Fundação Arthur Bernardes, 2009.

TORRES, R.A.; CORRÊA, G.S.S.; SILVA, M.A. et al. Desempenho de codornas EV2 para corte alimentadas com dietas com diferentes níveis de metionina + cistina durante a fase inicial. In: REUNIÃO ANUAL DA SOCIEDADE BRASILEIRA DE ZOOTECNIA, 42., 2005. Goiânia. Anais... Goiânia, GO:SBZ, 2005. 